\title{
Dry Cleaning Fluid
}

National Cancer Institute

\section{Source}

National Cancer Institute. Dry Cleaning Fluid. NCI Thesaurus. Code C122492.

Any of the non-water-based solvents used to remove soil and stains from clothes. The most common of these is tetrachloroethylene (perchloroethylene), a known human carcinogen. Alternative compounds include glycol ethers, petroleum-based solvents, liquid silicone (decamethylcyclopentasiloxane or D5), modified hydrocarbon blends, brominated solvents, and supercritical CO2. 